\section{Wind Pressures in Framed Structures with Semi-rigid Connections}

\author{
M. J. R. Guimarães \\ C. L. Sahlit \\ and J. L. V. Brito \\ Department of Civil Engineering \\ Brasília University \\ 70910-900 Brasília, DF. Brazil \\ miltonsf@unb.br \\ marlos@unb.br \\ clsahlit@terra.com.br \\ jlbrito@unb.br
}

In the analysis and design of framed structures, the traditional methods are based on the simplified assumption that the joints are completely either pinned or rigid. However, the experimental investigations show that the frame connections present an intermediate behaviour between these two extreme cases. The present work is concerned with the dynamic elastic analysis of semi-rigid plane frames subjected to wind pressures. The dynamic excitation induced by the wind is estimated by adopting the simulation method of Monte Carlo. The wind flutuation pressures are decomposed into a limited quantity of harmonic components that are then combined many times, making possible the accomplishment of a probabilistic analysis and the choice of a characteristic response. The frame is considered as a set of contiguous bar elements, connected to each other at the nodes, and the connections are modelled as zero-length rotational springs. A nodal description of the kinetic and kinematic laws is given under the restriction of small displacements. The behaviour of the frame material and connections is described by linear elastic moment-rotation relationships, which are presented in the stiffness form. In order to take into account the effect of the semi-rigid behaviour of beam-to-column connections, the mass and stiffness matrices are developed as the sum of the conventional finite element matrices and correction matrices that incorporate the flexibility of the end joints. The problem of forced vibrations is then solved by means of the numerical integration of the motion equations.

Keywords: Semi-rigid frames, wind forces, vibration analysis, dynamic response

\section{Introduction}

The methods commonly used in the analysis and project of framed structures are developed under the supposition of a simplified behavior of the connections between beams and columns. The joint is considered either totally pinned (pinned-joint connection) or totally rigid (rigid-joint connection). However, the experimental investigations show that most connections present an intermediate behavior between these two extreme cases; due to this fact, they should, therefore, be classified as semi-rigid (Stelmack et al., 1986; Lee \& Moon, 2002; Popov \& Takhirov, 2002). The semirigid connection is the one that has a capacity of moment transmission intermediate between the rigid and the pinned ones. It permits that, under the action of a load, the interconnected elements present a relative rotation and can transmit part of the active moment among them.

A connection beam-to-column of plane frame can be modeled considering three degrees of freedom. However, as the influence of the shear and axial deformations is, in general, small in relation to the rotational deformation (Jones et al., 1983), the behavior of the semi-rigid connection is described, in the present work, by the relation between the moment transmitted by it and the relative rotation between the two interconnected elements.

In spite of the behavior of most connections is not linear along all the moment-rotation curve, the linear approach is, in general, enough for the analysis of frames submitted to service loads (Lui \& Chen, 1987). Therefore, the moment-rotation relation of the connection is considered herein as being linear elastic.

The behavior of the connection is an important factor to be considered in the analysis of frames submitted to dynamic loads (Osman et al., 1993). However, the literature on the dynamic analysis of semi-rigid structures is still very limited. Shi \& Atluri (1989) and Chan \& Ming Ho (1994) proposed methods for analysis of free vibrations of semi-rigid frames, without however coming up with the coefficients of the involved elementary matrices. The influence of the flexibility of the joints in the free vibrations of framed structures was studied by Soares Filho \& Sahlit (1997a).

Paper accepted March, 2004. Technical Editor: Edgar Nobuo Mamiya.
These authors analyzed the behavior of semi-rigid structures subject to dynamic excitation considering, initially, the moment-rotation relationship of the connection as being linear elastic (Sahlit \& Soares Filho, 1997) and, soon afterwards, assuming that the semirigid connections can be characterized by similar relations to the governing equations of an elastic, perfectly plastic material, using then the optimization methods of the mathematical programming (Soares Filho \& Sahlit, 1997b).

The present work is concerned with the dynamic elastic analysis of semi-rigid plane frames subjected to wind pressures. The frame is considered as a set of contiguous bar elements, connected to each other at the nodes, and the connections are modeled as zero-length rotational springs. A nodal description of the kinetic and kinematic laws is given under the restriction of small displacements. The behavior of the frame material and connections is described by linear elastic moment-rotation relationships, which are presented in the stiffness form.

In order to take into account the effect of the semi-rigid behavior of beam-to-column connections, the mass and stiffness matrices are developed as the sum of the conventional finite element matrices and correction matrices that incorporate the flexibility of the end joints.

The dynamic excitation induced by the wind is estimated by adopting the Monte Carlo simulation method. This technique consists basically in the simulation of wind fluctuating pressures that are obtained from a local wind spectrum. The fluctuating pressures are decomposed into a limited quantity of harmonic components which are then combined many times for a possible gust center. For each combination obtained, a value of a relevant response is registered. Taking a reasonable quantity of relevant response values into consideration, a characteristic value is obtained by means of a statistic analysis, in which a probability of $95 \%$ of occurrence is considered. The random combination of the harmonic components, corresponding to the response value which is the nearest to the characteristic value, furnishes the characteristic wind excitation which simulates the wind fluctuating behavior.

The problem of forced vibrations is then solved by means of the numerical integration of the motion equations. Numerical results are presented and it is shown that the consideration of semi-rigid connections significantly alters the dynamic behavior of elastic framed structures subjected to wind loads. 


\section{Nomenclature}

\section{Latin Letters}

$L=$ lengh of element

$x_{i}^{b}=$ deformation of the bar (element)

$x_{i}^{c}=$ deformation of the connection

$x_{i}=$ total deformation

$k_{i}=$ stiffness connection

$X_{i}=$ bending moment

$q_{i}(t)=$ cinematic nodal displacement

$t=$ time

$E$ = elasticity modulus

$\boldsymbol{I}=$ identity matrix

$\boldsymbol{B}=$ matrix of the effect of the flexibility of semi-rigid connections

$\boldsymbol{M}_{\mathbf{0}}=$ conventional consistent-mass matrix

$\bar{M}=$ modified consistent-mass matrix

$\bar{m}=$ mass for unit of length

$P_{i}=$ fixity factor of semi-rigid connection

$R_{i}=$ stiffness index of semi-rigid connection

$W_{T}=$ total potential energy

$E I=$ flexural stiffness

$\mathbf{u}(\boldsymbol{t})=$ vector of the dynamic nodal displacements

$\bar{M}_{g}=$ global mass matrix

$\bar{C}_{g}=$ global damping matrix

$\bar{K}_{g}=$ global stiffness matrix

$\bar{a}_{i}=$ proportionality factors

$V_{0}=$ basic wind velocity

$V_{K}=$ characteristic wind velocity

$S_{1}$ and $S_{3}=$ statistical factors

$S_{2}=$ topografic factor

$q(\mathrm{z})=$ dynamic pressure at the heigth $\mathrm{z}$

$\mathrm{Ca}=$ drag coefficient

$\mathrm{Fa}=$ wind drag force

$b, \mathrm{Fr}$ and $p=$ meteorological factors

$A e=$ frontal area of the structure

$p_{600}=$ mean pressure

$p_{3}=$ peak pressure

$f=$ frequency

$S(f)=$ power spectrum of wind velocity

$u_{*}=$ friction velocity

$U_{0}=$ mean wind velocity at $10 \mathrm{~m}$ high

$S p^{\prime}(z, f)=$ power spectrum of fluctuating pressures

$c_{a r}=$ aerodynamic coefficient

$U \mathrm{z}=$ mean velocity at the heigth $\mathrm{z}$

$\mathrm{Uy} 1=$ top displacement

$p^{\prime}(t)=$ fluctuating pressures

Greek Symbols

$w(y, t)=$ field of displacements

$\Psi_{i}(y)=$ form functions

$\xi=$ damping ratio

$\lambda_{g}(t)=$ vector of the applied nodal loads

$\omega_{i}=$ frequencies of vibration

$\phi_{i}=$ natural vibration modes

$\rho=$ air density

$\sigma^{2}\left(p^{\prime}\right)=$ mean square value of $p^{\prime}(t)$

$\Delta z_{0 k}=$ gust dimension

\section{Mass Matrix}

Consider the structural element, of length $\mathrm{L}$, with semi-rigid connections shown in Fig. 1, where $\mathrm{x}_{i}^{b}$ is the deformation of the bar (element), $\mathrm{x}_{i}^{c}$ is the connection deformation and $x_{i}$ is the total deformation, that is, the relative rotation between the linked elements by the connection.

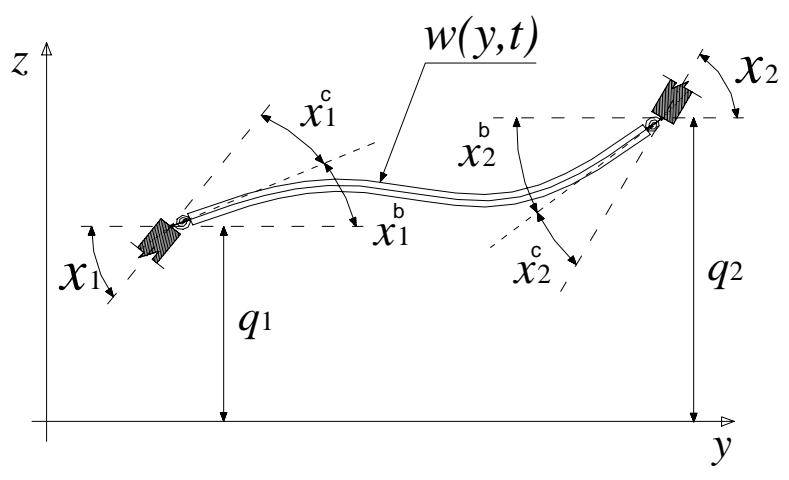

Figure 1. Deformed structural element with semi-rigid connections.

From Fig. 1, the total deformation may be written as

$$
x_{i}=x_{i}^{b}+x_{i}^{c}
$$

where the connection deformation $x_{i}^{c}$, introduced by its flexibility, depends on the rigidity of the connection $k_{i}$ and the bending moment $X_{i}$, being given by

$$
x_{i}^{c}=\frac{X_{i}}{k_{i}}
$$

For the dynamic analysis of a beam element, the field of the displacements $w(y, t)$ can be defined in terms of four form functions $\Psi_{i}(y)$ and of the nodal displacements $q_{1}(t), x_{1}{ }^{b}(t), q_{2}(t)$ and $x_{2}{ }^{b}(t)$, in the instant of time $t$, as

$$
w(y, t)=\psi(y) q(t)=\left[\begin{array}{llll}
\Psi_{1}(y) & \Psi_{2}(y) & \Psi_{3}(y) & \Psi_{4}(y)
\end{array}\right]\left[\begin{array}{c}
q_{1}(t) \\
x_{1}^{b}(t) \\
q_{2}(t) \\
x_{2}^{b}(t)
\end{array}\right]
$$

where

$$
\begin{gathered}
\Psi_{1}(y)=\frac{2 y^{3}}{L^{3}}-\frac{3 y^{2}}{L^{2}}+1 \\
\Psi_{2}(y)=\frac{y^{3}}{L^{2}}-\frac{2 y^{2}}{L}+y \\
\Psi_{3}(y)=-\frac{2 y^{3}}{L^{3}}+\frac{3 y^{2}}{L^{2}} \\
\Psi_{4}(y)=\frac{y^{3}}{L^{2}}-\frac{y^{2}}{L}
\end{gathered}
$$


Taking into account the additional rotation due to the connection, Eq. (2), the field of displacements, Eq. (3), for a beam element with semi-rigid joints becomes

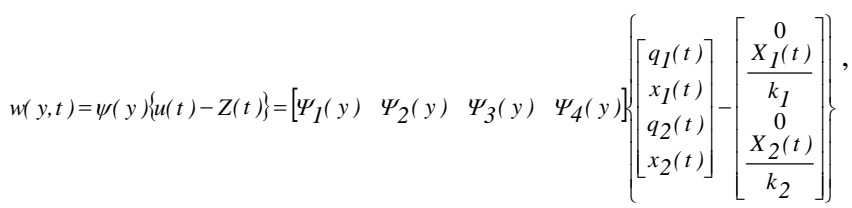

Considering the form functions (4) and replacing (5) into

$$
\begin{aligned}
& X_{1}(t)=-\left.E I w^{\prime \prime}(y, t)\right|_{y=0} \\
& X_{2}(t)=\left.\operatorname{EIw}^{\prime \prime}(y, t)\right|_{y=L}
\end{aligned}
$$

the following equations may be obtained

$$
\left[\begin{array}{cc}
1+4 W_{1} & 2 W_{2} \\
2 W_{1} & 1+4 W_{2}
\end{array}\right]\left[\begin{array}{l}
X_{1}(t) \\
X_{2}(t)
\end{array}\right]=\frac{E I}{L^{2}}\left[\begin{array}{cccc}
6 & 4 L & -6 & 2 L \\
6 & 2 L & -6 & 4 L
\end{array}\right]\left[\begin{array}{c}
q_{1}(t) \\
x_{1}(t) \\
q_{2}(t) \\
x_{2}(t)
\end{array}\right]
$$

where $R_{i}=L k_{i} / E I=1 / W_{i}$ represents the stiffness index of the connection at the end $i(i=1,2)$.

Admitting that $\Delta=\left[\left(1+4 W_{1}\right)\left(1+4 W_{2}\right)-4 W_{1} W_{2}\right]$ and after some algebraic manipulations, the Eq. (7) may be written as

$\left[\begin{array}{l}X_{1}(t) \\ X_{2}(t)\end{array}\right]=\frac{E I}{L^{2} \Delta}\left[\begin{array}{cccc}6\left(1+2 W_{2}\right) & 4 L\left(1+3 W_{2}\right) & -6\left(1+2 W_{2}\right) & 2 L \\ 6\left(1+2 W_{1}\right) & 2 L & -6\left(1+2 W_{1}\right) & 4 L\left(1+3 W_{1}\right)\end{array}\right]\left[\begin{array}{c}q_{1}(t) \\ x_{1}(t) \\ q_{2}(t) \\ x_{2}(t)\end{array}\right]$

Introducing Eq. (8) into Eq. (5) of the field of displacements, $w(y, t)$, and considering that

$B_{1}^{T}=\left[\begin{array}{llll}-\frac{6}{L}\left(W_{1}+2 W_{1} W_{2}\right) & -4\left(W_{1}+3 W_{1} W_{2}\right) & \frac{6}{L}\left(W_{1}+2 W_{1} W_{2}\right) & -2 W_{1}\end{array}\right]$

and

$B_{2}{ }^{T}=\left[\begin{array}{llll}-\frac{6}{L}\left(W_{2}+2 W_{1} W_{2}\right) & -2 W_{2} & \frac{6}{L}\left(W_{2}+2 W_{1} W_{2}\right) & -4\left(W_{2}+3 W_{1} W_{2}\right)\end{array}\right]$

the following relation is obtained

$$
\boldsymbol{Z}(t)=\frac{-1}{\Delta} \boldsymbol{B} \boldsymbol{u}(t)=\frac{-1}{\Delta}\left[\begin{array}{c}
0^{T} \\
\boldsymbol{B}_{1}{ }^{T} \\
0^{T} \\
\boldsymbol{B}_{2}{ }^{T}
\end{array}\right]\left[\begin{array}{c}
q_{1}(t) \\
x_{1}(t) \\
q_{2}(t) \\
x_{2}(t)
\end{array}\right]
$$

Finally, the field of the displacements $w(y, t)$ can be expressed in terms of the nodal displacements $q_{1}(t)$ and $q_{2}(t)$ and of the end rotations $x_{1}(t)$ e $x_{2}(t)$ as

$$
w(y, t)=\psi(y)\left\{\boldsymbol{I}+\frac{1}{\Delta} \boldsymbol{B}\right\} \boldsymbol{u}(t)
$$

where the presence of the matrix $\boldsymbol{B}$ reflects the effect of the flexibility of the semi-rigid connections. It is important to note that, if the connections are rigid, all the terms in $\boldsymbol{B}$ will be zero and $\mathrm{Eq}$. (12) will be reduced to the classic definition of the displacement field in terms of the nodal displacements.

To obtain a consistent-mass matrix of a disconnected element with semi-rigid joints, it is used the expression of the kinetic energy $T$ for a beam element with mass per unit of length $\bar{m}$, which is

$$
T=\frac{1}{2} \int_{0}^{L} \bar{m}(y)[\dot{w}(y, t)]^{2} d y
$$

Evaluating the first time derivatives of the field of displacements, Eq. (12), and replacing the result in Eq. (13) one gets

$T=\frac{1}{2}[\dot{\boldsymbol{u}}(t)]^{T}\left[\boldsymbol{I}+\frac{1}{\Delta} \boldsymbol{B}^{T}\right]\left\{\int_{0}^{L} \bar{m}(y)[\psi(y)]^{T} \psi(y) d y\right\}\left[\boldsymbol{I}+\frac{1}{\Delta} \boldsymbol{B}\right] \dot{\boldsymbol{u}}(t)$

The integral in Eq. (14) denotes the conventional consistentmass matrix $\boldsymbol{M}_{0}$. Hence, this equation can be rewritten as

$$
T=\frac{1}{2}[\dot{\boldsymbol{u}}(t)]^{T}\left\{\boldsymbol{M}_{0}+\boldsymbol{M}_{0} \frac{1}{\Delta} \boldsymbol{B}+\frac{1}{\Delta} \boldsymbol{B}^{T} \boldsymbol{M}_{0}+\frac{1}{\Delta} \boldsymbol{B}^{T} \boldsymbol{M}_{0} \frac{1}{\Delta} \boldsymbol{B}\right\} \dot{\boldsymbol{u}}(t)
$$

The kinetic energy is then expressed as

$$
T=\frac{1}{2}[\dot{\boldsymbol{u}}(t)]^{T}\left\{\boldsymbol{M}_{0}+\boldsymbol{M}_{1}\right\} \dot{\boldsymbol{u}}(t)
$$

where

$$
\boldsymbol{M}_{1}=\boldsymbol{M}_{0} \frac{1}{\Delta} \boldsymbol{B}+\frac{1}{\Delta} \boldsymbol{B}^{T} \boldsymbol{M}_{0}+\frac{1}{\Delta} \boldsymbol{B}^{T} \boldsymbol{M}_{0} \frac{1}{\Delta} \boldsymbol{B}
$$

represents the matrix of correction of the conventional consistentmass matrix so as to take into consideration the presence of semirigid connections. The consistent-mass matrix $\overline{\boldsymbol{M}}$, modified by the inclusion of semi-rigid joints, is given therefore by the sum of the two matrices $\boldsymbol{M}_{0}$ and $\boldsymbol{M}_{1}$.

The presence of the semi-rigid joints does not affect the stiffness coefficients related to the axial effects. Therefore, the mass matrix of an element with semi-rigid joints is given by

$$
\begin{aligned}
& \overline{\boldsymbol{M}}=\frac{\bar{m} L}{420 D^{2}}
\end{aligned}
$$

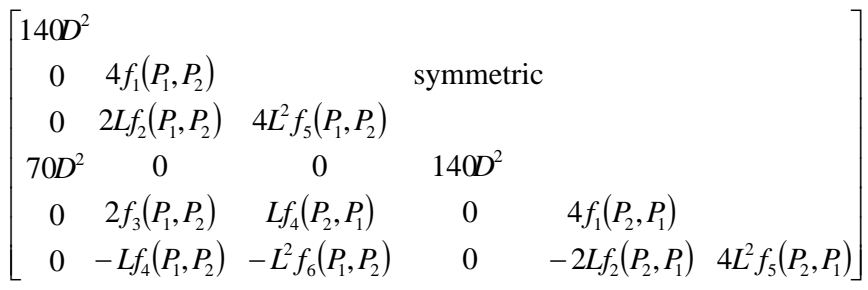

where

$$
D=4-P_{1} P_{2}
$$




$$
\begin{aligned}
& f_{1}\left(P_{1}, P_{2}\right)=\left(560+224 P_{1}+32 P_{1}^{2}-196 P_{2}-328 P_{1} P_{2}-\right. \\
& 55 P_{1}^{2} P_{2}+32 P_{2}^{2}+50 P_{1} P_{2}^{2}+32 P_{1}^{2} P_{2}^{2} \text { ) } \\
& f_{2}\left(P_{1}, P_{2}\right)=\left(224 P_{1}+64 P_{1}^{2}-160 P_{1} P_{2}-86 P_{1}^{2} P_{2}+32\right. \\
& P_{1} P_{2}{ }^{2}+25 P_{1}^{2} P_{2}^{2} \text { ) } \\
& f_{3}\left(P_{1}, P_{2}\right)=\left(560-28 P_{1}-64 P_{1}^{2}-28 P_{2}-184 P_{1} P_{2}+5 P_{1}^{2} P_{2}-64 P_{2}^{2}+5\right. \\
& P_{1} P_{2}^{2}+41 P_{1}^{2} P_{2}^{2} \text { ) } \\
& f_{4}\left(P_{1}, P_{2}\right)=\left(392 P_{2}-100 P_{1} P_{2}-64 P_{1}^{2} P_{2}-128 P_{2}^{2}-\right. \\
& 38 P_{1} P_{2}{ }^{2}+55 P_{1}^{2} P_{2}^{2} \text { ) } \\
& f_{5}\left(P_{1}, P_{2}\right)=\left(32 P_{1}^{2}-31 P_{1}^{2} P_{2}+8 P_{1}^{2} P_{2}^{2}\right) \\
& f_{6}\left(P_{1}, P_{2}\right)=\left(124 P_{1} P_{2}-64 P_{1}^{2} P_{2}-64 P_{1} P_{2}^{2}+31 P_{1}^{2} P_{2}^{2}\right)
\end{aligned}
$$

In Eqs. (19a-g), $P_{i}(i=1,2)$ is the fixity factor of semi-rigid connection at the end $i$, defined in relation to the stiffness index $R_{i}$ as

$$
P_{i}=\frac{R_{i}}{3+R_{i}}
$$

\section{Stiffness Matrix}

Considering the relation of the displacement field (12), the stiffness matrix of a disconnected element with semi-rigid joints may be obtained. For that, the expression of the total potential energy $W_{T}$ is used for a beam element, modifying the expression of the kinetic energy (13). This expression, for an element with flexural stiffness $E I$, is composed of two parts: one, due to the elastic deformation of the beam, which can be written as

$$
W_{v}=\frac{1}{2} \int_{0}^{L} E I\left[w^{\prime \prime}(y, t)\right]^{2} d y
$$

and another, which is due to the rotational flexibility of the connection, given by

$$
W_{c}=\frac{1}{2} k_{1}\left[x_{1}^{c}\right]^{2}+\frac{1}{2} k_{2}\left[x_{2}^{c}\right]^{2}
$$

By replacing the second derivative of Eq. (12) in relation to $y$ in Eq. (21), it follows that

$$
\left.W_{v}=\frac{1}{2}[\boldsymbol{u}(t)]^{T}\left[\boldsymbol{I}+\frac{1}{\Delta} \boldsymbol{B}^{T}\right] \iint_{0}^{L} E I\left[\psi^{\prime \prime}(y)\right]^{T}\left[\psi^{\prime \prime}(y)\right] d y\right\}\left[\boldsymbol{I}+\frac{1}{\Delta} \boldsymbol{B}\right] \boldsymbol{u}(t)
$$

Knowing that the integral in Eq. (23) denotes the conventional stiffness matrix $\boldsymbol{K}_{0}$, for instance (Paz, 1992), this relation may be rewritten as

$W_{v}=\frac{1}{2}[\boldsymbol{u}(t)]^{T}\left\{\boldsymbol{K}_{0}+\boldsymbol{K}_{0} \frac{1}{\Delta} \boldsymbol{B}+\frac{1}{\Delta} \boldsymbol{B}^{T} \boldsymbol{K}_{0}+\frac{1}{\Delta} \boldsymbol{B}^{T} \boldsymbol{K}_{0} \frac{1}{\Delta} \boldsymbol{B}\right\} \boldsymbol{u}(t)$

Considering that

$$
\boldsymbol{K}_{1}=\boldsymbol{K}_{0} \frac{1}{\Delta} \boldsymbol{B}+\frac{1}{\Delta} \boldsymbol{B}^{T} \boldsymbol{K}_{0}+\frac{1}{\Delta} \boldsymbol{B}^{T} \boldsymbol{K}_{0} \frac{1}{\Delta} \boldsymbol{B}
$$

the potential energy due to the elastic deformation of the beam is then expressed as

$$
W_{v}=\frac{1}{2}[\boldsymbol{u}(t)]^{T}\left\{\boldsymbol{K}_{0}+\boldsymbol{K}_{1}\right\} \mathbf{u}(t)
$$

On the other hand, it is known from Eq. (2) that

$$
x_{i}^{c}=\frac{X_{i}}{k_{i}}=\frac{-1}{\Delta} \boldsymbol{B}_{i}^{T} \boldsymbol{u}(t)
$$

Introducing Eq. (27) into Eq. (22), it follows that

$$
W_{c}=\frac{1}{2}[\boldsymbol{u}(t)]^{T}\left[k_{1} \boldsymbol{B}_{1} \boldsymbol{B}_{1}^{T}+k_{2} \boldsymbol{B}_{2} \boldsymbol{B}_{2}{ }^{T}\right] \frac{\boldsymbol{u}(t)}{\Delta^{2}}
$$

Calling

$$
\boldsymbol{K}_{2}=k_{1} \boldsymbol{B}_{1} \boldsymbol{B}_{1}^{T}+k_{2} \boldsymbol{B}_{2} \boldsymbol{B}_{2}{ }^{T} / \Delta^{2}
$$

the expression of the total potential energy may be obtained as

$$
W_{T}=W_{v}+W_{c}=\frac{1}{2}[\boldsymbol{u}(t)]^{T}\left\{\boldsymbol{K}_{0}+\boldsymbol{K}_{1}+\boldsymbol{K}_{2}\right\} \mathbf{u}(t)
$$

where $\boldsymbol{K}_{1}$ and $\boldsymbol{K}_{2}$ represent the correction matrices of the conventional stiffness matrix so as to take the presence of semi-rigid connections into consideration. The stiffness matrix modified by the inclusion of semi-rigid joints is obtained therefore through the sum of three matrices

$$
\overline{\boldsymbol{K}}=\boldsymbol{K}_{0}+\boldsymbol{K}_{1}+\boldsymbol{K}_{2}
$$

As for the mass matrix, the presence of semi-rigid joints does not affect the stiffness coefficients related to the axial effects. Therefore, the stiffness matrix of the element with semi-rigid joints is

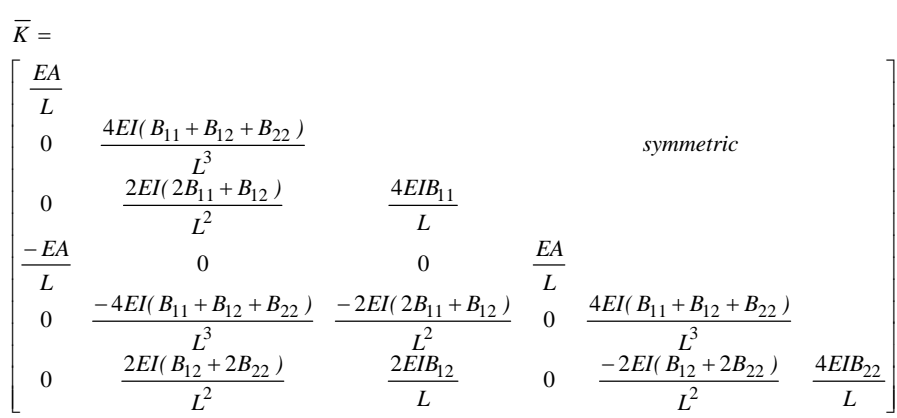

where

$$
\begin{aligned}
& B_{11}=\frac{3 P_{1}}{4-P_{1} P_{2}} \\
& B_{12}=\frac{3 P_{1} P_{2}}{4-P_{1} P_{2}} \\
& B_{22}=\frac{3 P_{2}}{4-P_{1} P_{2}}
\end{aligned}
$$




\section{Equations of Motion of the Dynamic System}

The equations of motion for the analysis of forced vibrations of a structure with semi-rigid connections may be expressed as

$$
\overline{\boldsymbol{M}}_{g} \ddot{\boldsymbol{u}}(t)+\overline{\boldsymbol{C}}_{g} \dot{\boldsymbol{u}}(t)+\overline{\boldsymbol{K}}_{g} \boldsymbol{u}(t)=\lambda_{g}(t)
$$

where $\overline{\boldsymbol{M}}_{g}, \overline{\boldsymbol{C}}_{g}$ and $\overline{\boldsymbol{K}}_{g}$, of order (n x n), are respectively the global mass, damping and stiffness matrices of the structure, obtained from the matrices of the structural elements, properly modified by the presence of semi-rigid joints; $\ddot{\mathbf{u}}, \dot{\mathbf{u}}$ and $\mathbf{u}$, of order ( $n \times 1)$, are respectively the nodal acceleration, velocity and displacement vectors of the structure; and $\lambda_{g}(t)$ is the vector, of order ( $n \times 1)$, of the applied nodal loads. The system (34) is solved, in the present work, by the numeric integration scheme of Newmark.

For the forced vibration analysis, the typical expression for the damping matrix, called Rayleigh damping matrix,

$$
\overline{\boldsymbol{C}}_{g}=\bar{a}_{0} \overline{\boldsymbol{M}}_{g}+\overline{\boldsymbol{a}}_{1} \overline{\boldsymbol{K}}_{g}
$$

is used, where $\bar{a}_{0}$ and $\bar{a}_{1}$ are proportionality factors that can be obtained by means of two natural frequencies of vibration and corresponding damping ratios $\xi$.

When the applied forces in the structure are null, $\lambda_{g}(t)=\mathbf{0}$, the solution of Eq. (34) turns into an eigenvalue or characteristic value problem, given by

$$
\left(\overline{\boldsymbol{K}}_{g}-\omega^{2} \overline{\boldsymbol{M}}_{g}\right) \phi=0
$$

whose solution provides the values of the natural frequencies of vibration $\omega_{i}$ and their corresponding natural vibration modes $\phi_{i}$ $(i=1, \ldots, n)$. In the present work, the Jacobi method is used for the calculation of the eigenvalues and corresponding eigenvectors or mode shapes.

\section{Characteristic Wind Excitation by the Simulation Method of Monte Carlo}

In the simulation method of Monte Carlo, the fluctuating pressures of the wind are generated starting from a given wind spectrum, where the fluctuating pressure is decomposed into a limited quantity of harmonic components. These are then combined many times for a possible gust center and, in each combination, a value of the relevant response of top displacement, in the present case, is registered.

Thus, a considerable quantity of values of this response is at disposal, making a statistical analysis possible in order to obtain a characteristic value, corresponding to a probability of $5 \%$ of being exceeded. Defined this characteristic value, the random combination of the harmonic forces can be determined whose maximum response is the nearest to the characteristic one. Finally, the structure is again excited by this random combination and the characteristic values for all displacements and member forces are then obtained with good approximation (Franco, 1993; Guimarães, 2000).

\section{Aerodynamic Loads}

The aerodynamic loads are obtained, in the present work, from the continuous profile of the dynamic pressures, according to the procedure proposed by Blessmann (1988), considering the values of the basic wind velocity $V_{o}$, the topographical and statistical factors $S_{1}$ and $S_{3}$ respectively, the meteorological parameters $b, \mathrm{Fr}$ and $p$, and the drag coefficients $\mathrm{Ca}$, all provided by the Brazilian Code NBR-6123 (1987) and taking into account, besides, the geometric parameters of the construction.

The characteristic wind velocity, $V_{k}$, is obtained by the expression

$$
V_{k}=V_{o} S_{1} S_{2} S_{3}
$$

being the factor $S_{2}$, at the heigth $\mathrm{z}$, given by

$$
S_{2}=b F_{r}(z / 10)^{p}
$$

The dynamic pressure can then be calclated as

$$
q(z)=\frac{V_{k}^{2}}{1.6}
$$

where $q(\mathrm{z})$ is given in $\mathrm{N} / \mathrm{m}^{2}$ and $V_{k}$ in $\mathrm{m} / \mathrm{s}$.

The wind drag force, $F a$, at each pavement level is given by

$$
F a=C a q(z) A e
$$

where $A e$ is the frontal area of the structure exposed to the wind.

\section{Simulation of Monte Carlo}

The mean wind is conventionally measured in time intervals that vary from 10 minutes to 1 hour. Many codes, however, among which the Brazilian Code, define values for the peak velocity measured in very short time intervals (2 to 5 seconds) (Franco, 1993).

Starting from these values, which are practically instantaneous, it is possible to determine the mean velocity measured in a time interval of, say, 10 minutes. Thus, it is possible to obtain a ratio between the mean pressure and the fluctuating maximal pressure through the graph shown in Fig. 2. The ratio between the mean pressure, considered when $t=600 \mathrm{~s}$ and the peak one, assuming $t=3$ s, will be given by

$$
\frac{p_{600}}{p_{3}}=\frac{(1 / 2) \rho V_{600}^{2}}{(1 / 2) \rho V_{3}^{2}}=\frac{V_{600}^{2}}{V_{3}^{2}}=\left(\frac{V_{600}}{V_{3}}\right)^{2}=(0.69)^{2}=0.48
$$

meaning that $48 \%$ of the total pressure is constant and $52 \%$ is due to the fluctuating pressures.

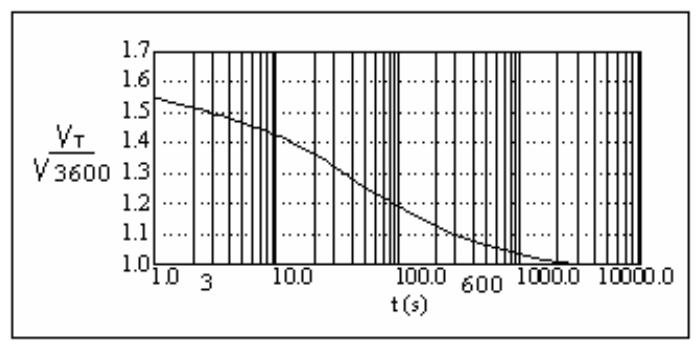

Figure 2. Equivalence between hourly wind and average wind on $t$ seconds.

It is adopted, in this work, the spectrum of fluctuating velocities proposed by the National Building Code of Canada (1985), which consists of a variant of the expression introduced by Davenport (1963). Thus, the power spectrum is expressed as 


$$
\frac{f S(f)}{u_{*}^{2}}=4 \frac{x^{2}}{\left(1+x^{2}\right)^{4 / 3}} ; \quad x=\frac{1220 f}{U_{0}}
$$

where $U_{o}$ is the mean wind velocity at $10 \mathrm{~m}$ high in an open terrain, $u_{*}$ is the friction velocity and $f$ is the frequency in $\mathrm{Hz}$.

Assuming that the intensity of the turbulence is low, the spectral density function of the fluctuating pressures $S_{p},(z, f)$ can be written as a function of the velocity spectrum as

$$
S_{p^{\prime}}(z, f)=\left(\rho c_{a r} U_{z}\right)^{2} S(z, f)
$$

where $\rho$ is the air density, $c_{a r}$ is the aerodynamic coefficient at the considered point and $U z$ is the mean velocity at the height $\mathrm{z}$.

With sufficient precision, the spectrum of fluctuating pressures can be considered as being proportional to the spectrum of velocities as

$$
S_{p^{\prime}}(z, f)=P[S(z, f)] ; \quad P=\left(\rho c_{a r} U_{z}\right)^{2}
$$

The fluctuating pressure $p^{\prime}(t)$ at all points of the structure corresponds to $52 \%$ of the total pressure $p(t)$, constituting a random, stationary, ergodic and gaussian process. The pressure $p^{\prime}(t)$ may be represented through a Fourier integral as

$$
p^{\prime}(t)=\int_{-\infty}^{+\infty} C(f) \cos [2 \pi f t-\theta(f)] d f
$$

where

$$
\begin{gathered}
C(f)=\sqrt{A^{2}(f)+B^{2}(f)} \\
\theta(f)=\tan ^{-1} \frac{B(f)}{A(f)} \\
A(f)=\int_{-\infty}^{\infty} p^{\prime}(t) \cos 2 \pi f t d t \\
B(f)=\int_{-\infty}^{\infty} p^{\prime}(t) \sin 2 \pi f t d t
\end{gathered}
$$

The mean square value of $p^{\prime}(t)$, supposedly defined over a sufficiently long time interval $T$, is given by

$$
\sigma^{2}\left(p^{\prime}\right)=\frac{1}{T} \int_{-T / 2}^{T / 2} p^{\prime 2}(t) d t=\frac{2}{T} \int_{0}^{\infty} C^{2}(f) d f
$$

If $T \rightarrow \infty$, the following equation may be written

$$
\sigma^{2}\left(p^{\prime}\right)=\int_{0}^{\infty} S_{p^{\prime}}(z, f) d f
$$

where $S_{p^{\prime}}(z, f)$ is the spectral density function of $p^{\prime}(t)$ and $S_{p^{\prime}}(z, f) d(f)$ represents the elementary contribution, associated to the frequency interval $d f$, to the mean square value.

Instead of an infinite number of functions, $p^{\prime}(t)$ may be represented in an approximate way by a finite number $m$ of harmonical functions, conveniently chosen in such a way that their periods span uniformly over the time interval of interest, which goes from 600 to 0.5 seconds. Franco (1993) proposes the use of, at least, eleven harmonical functions $(m \geq 11)$, having the period of one of them coinciding with the fundamental period of the structure and the other periods taken as multiple of the fundamental period.

The Equation (45) now becomes

$$
p^{\prime}(t) \cong \sum_{k=1}^{m} C_{k} \cos \left(\frac{2 \pi}{T_{r} r_{k}} t-\theta_{k}\right)
$$

where the coefficients $C_{k}$ and $r_{k}$ are given by

$$
\begin{gathered}
C_{k}=\sqrt{2 \int_{(k)} S_{p^{\prime}}(z, f) d f} \\
r_{k}=2^{k-r}
\end{gathered}
$$

being $r$ the index of the resonant component and $r_{k}$ the index of the other components.

The maximal amplitude of the fluctuating pressure is $p^{\prime}(t)=0.52 p$. Now the amplitudes for the $m$ harmonic components of $p^{\prime}(t)$ are given by

$$
p_{k}^{\prime}=\frac{C_{k}}{\sum_{k=1}^{m} C_{k}} p^{\prime}=c_{k} p^{\prime}
$$

The random nature of the process is characterized by the random combination of the phase angles of the $m$ harmonical functions.

To obtain the spatial correlation between velocities and fluctuating pressures, the concept of gust dimension is used. Thus, the height $\Delta z_{o k}$ of the equivalent gust can be given by

$$
\Delta z_{0 k}=2 \int_{0}^{\infty} \exp \left(-\frac{14 \Delta z f_{k}}{U_{0}}\right) d(\Delta z)=\frac{U o}{7 f_{k}}
$$

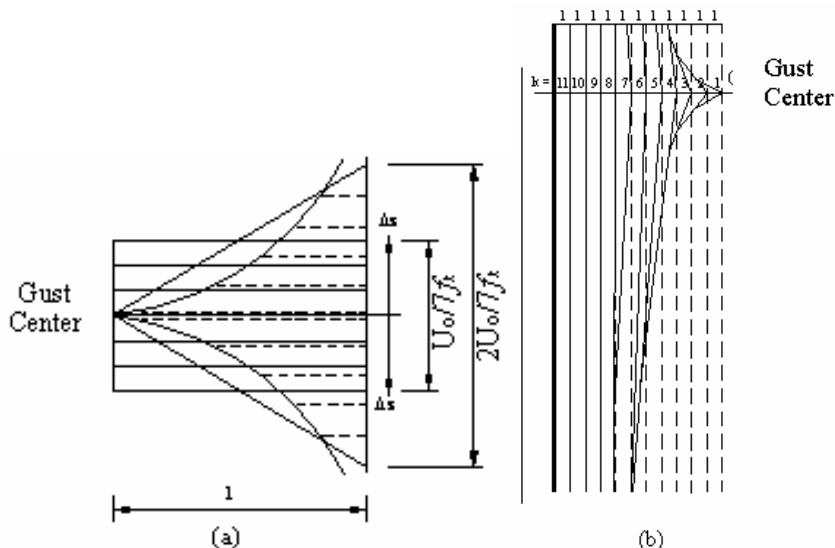

Figure 3. Equivalent gusts (a) and reduction coefficients of fluctuating pressures (b).

The gust of frequency $f_{k}$, whose correlation coefficients are represented by double exponential curves, may be approximated by the perfectly correlated gust of height $\Delta z_{o k}=U_{o} / 7 f_{k}$, or, as it is used in the present work, by the gust defined by two triangles which implies in a decaying linear correlation from 1 to 0 in an area with total length of $2 \Delta z_{o k}=2 U_{o} / 7 f_{k}$, according to Fig. 3-a.

The smaller the frequency $f_{k}$ of the considered fluctuating component, the greater the height of its area of aerodynamic influence will be. 
In the present work, the gust center is adopted as located at $85 \%$ of the structure height. Thus, the fluctuating pressures should be multiplied by the linear decaying coefficient, as in Fig. 3-b, whose value varies from 1 to 0 .

Once chosen a relevant generalized coordinate, which in the present case is the top displacement, the structure was simultaneously excited by the $m$ functions, with random phase angles $\theta_{\mathrm{k}}$. For each combination of $\theta_{\mathrm{k}}$ values, an analysis in the time domain, corresponding to the duration of the gust - which is supposed to be nearly 600 seconds - is taken place and the maximal value of the relevant coordinate is determined.

With the several values of top displacement $U y 1$, the characteristic value of the associated response to this coordinate will be evaluated by means of a statistical analysis assuming type I extremes distribution (Gumbel), with 5\% of probability of being exceeded. In the present work, twenty analyses in the time domain have been done, which corresponds to twenty sets of random phase angles for each type of structural connection considered.

It is now necessary to determine the characteristic values of all the displacements and of the member forces in the structure. To achieve this purpose it suffices to select, among the random loading combination, one whose response is the nearest to the characteristic value of top displacement. By exciting the structure with this characteristic load, the characteristic values of response for the whole structure are found, and so is the dynamic analysis completed.

To obtain the final response, the combined analysis has been done considering $48 \%$ of the value of the response given by the static analysis, plus the characteristic value obtained from the Monte Carlo simulation.

\section{Numerical Results}

The dynamic analysis of a twenty floors steel frame with semirigid connections, subjected to wind pressures, is presented. The frame dimensions, in meters, are specified in Fig. 4. The semi-rigid connections are only considered in the connections of the beams with the columns, being assumed that they behave elastically and being taken into account two fixation factors: $P_{i}=0.5$ (semi-rigid joints) and $P_{i}=1.0$ (rigid joints).

The characteristics of the metallic profiles are shown in Table 1. It is used steel ASTM A-36, with modulus of elasticity $E=210.00 \mathrm{x}$ $10^{6} \mathrm{KN} / \mathrm{m}^{2}$ and density $\rho=78.255 \mathrm{KN} / \mathrm{m}^{3}$.

Table 1. Data of the metallic profiles used in the steel frame.

\begin{tabular}{|c|c|c|}
\hline Element & $\begin{array}{c}\text { Cross section } \\
\left(\mathrm{m}^{2}\right)\end{array}$ & $\begin{array}{c}\text { Moment of } \\
\text { inertia }\left(\mathrm{m}^{4}\right)\end{array}$ \\
\hline Columns ( $1^{\text {st }}$ to $4^{\text {th }}$ floors) & 0.08650 & 0.00300520 \\
\hline Columns (5 $5^{\text {th }}$ to $8^{\text {th }}$ floors) & 0.06520 & 0.00204370 \\
\hline Columns $\left(9^{\text {th }}\right.$ to $14^{\text {th }}$ floors) & 0.05010 & 0.00146930 \\
\hline Columns $\left(15^{\text {th }}\right.$ to $20^{\text {th }}$ floors) & 0.04010 & 0.00111134 \\
\hline Beams (all) & 0.01826 & 0.00087410 \\
\hline
\end{tabular}

It is aimed to study the influence of the semi-rigidity of the connections in the dynamic response of the structure, with regard to the values of the natural frequencies of vibration and corresponding modal forms, as well as the maximum displacements and distribution of structural internal forces produced by the wind action. The technique used to evaluate the active load at the structure in the direction of the wind is based on the method of simulation of Monte Carlo, as described in item 5. It is considered that the structure presents a damping ratio $\xi=0.05$. The time of analysis for each combination of the harmonic components of the wind is of 10 minutes, having been used a total of 85650 time steps with value $\Delta t=0.007 \mathrm{~s}$.

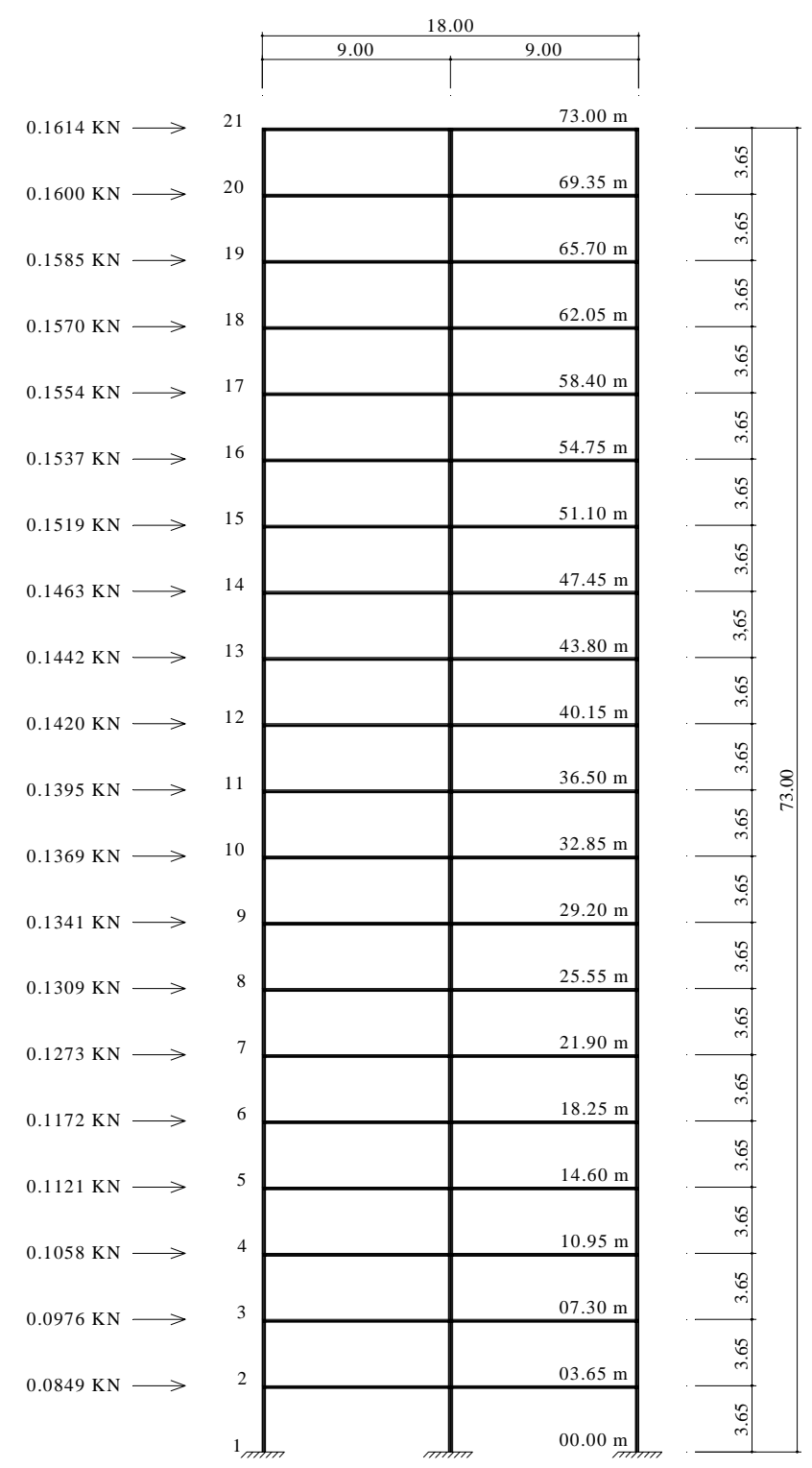

Figure 4. Steel frame of 20 floors under the action of the static wind load.

The static analysis of the structure was done by using a program of linear static analysis of plane frames with semi-rigid connections, developed by Soares Filho (1997). In this analysis, the static load of the wind was determined according to a procedure described in the Brazilian Code NBR-6123 (1987). Table 2 presents the values of the static horizontal displacements at the top frame, for the cases of rigid and semi-rigid joints.

Table 2. Static horizontal displacements of the node 21.

\begin{tabular}{|c|c|}
\hline Connection & Displacement $(\mathrm{m})$ \\
\hline Rigid $\left(P_{j}=1.0\right)$ & 0.11969 \\
\hline Semi-rigid $\left(P_{j}=0.5\right)$ & 0.256043 \\
\hline
\end{tabular}

Table 3 indicates the values of the first six natural frequencies of vibration for the frame, taking into consideration that the connections are rigid and, alternatively, being assumed that the connections beam-to-column are semi-rigid. As it can be observed, the flexibility of the connections alters significantly the values of the natural frequencies (Soares Filho, 1997). 
Table 3. Frequencies considering the two types of connections.

\begin{tabular}{|c|c|c|}
\hline \multirow{2}{*}{$\begin{array}{c}\text { Frequencies } \\
(\mathrm{rad} / \mathrm{s})\end{array}$} & \multicolumn{2}{|c|}{ Connection } \\
\cline { 2 - 3 } & Rigid $\left(P_{i}=1.0\right)$ & Semi-rigid $\left(P_{j}=0.5\right)$ \\
\hline$\omega_{1}$ & 4.850 & 3.350 \\
\hline$\omega_{2}$ & 15.439 & 10.152 \\
\hline$\omega_{3}$ & 25.102 & 17.307 \\
\hline$\omega_{4}$ & 35.691 & 25.257 \\
\hline$\omega_{5}$ & 47.010 & 34.826 \\
\hline$\omega_{6}$ & 59.674 & 45.998 \\
\hline
\end{tabular}

Figures 5 and 6 show the modal displacements of the left column of the frame, allowing the analysis the variations suffered by the first and second vibration modes, when the flexibility of the connections is taken into consideration.

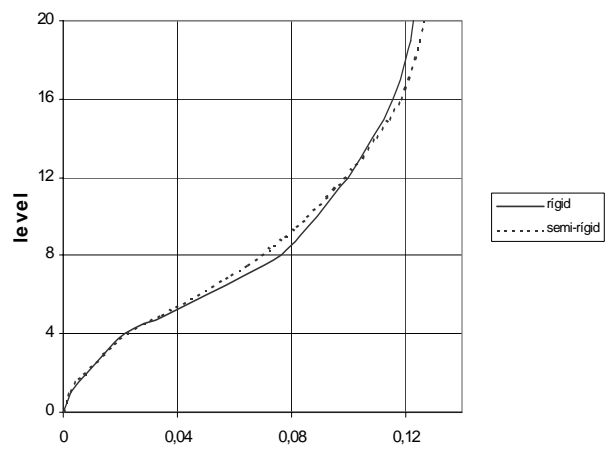

Figure 5. Variation in the first natural vibration mode.

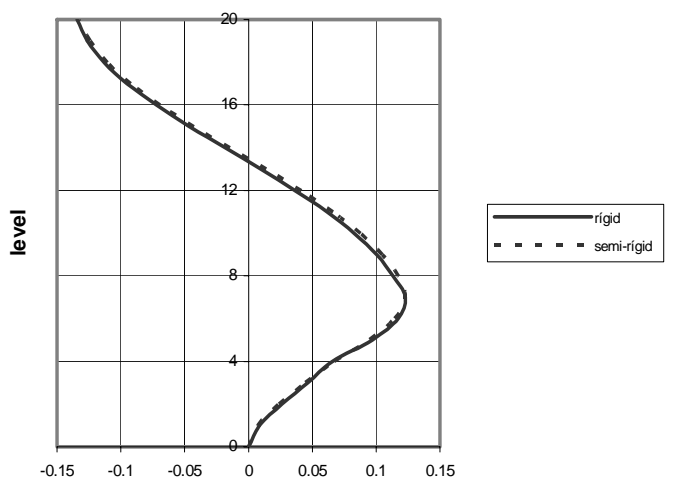

Figure 6. Variation in the second natural vibration mode.

In Table 4, the maximum responses of the top displacement are presented, one for each combination of the 20 blocks of random numbers (phase angles of the harmonic components), obtained from the analysis in the time domain for the rigid and semi-rigid structural models.

By using the values of the maximal displacements listed in Table 4, a probabilistic analysis is carried out (Gumbel - Type I): one for the rigid structure and another for the semi-rigid one, in which the characteristic values are determined, with a probability of $95 \%$ of occurrence. The results of the analysis can be seen in Table 5, where $\mu$ is the mean, $\sigma$ is the standard deviation; $p$ is the probability of occurrence of the characteristic value; $\varpi, \alpha$ and $x_{b}$ are parameters of Gumbel for extreme values; and $X c$ is the characteristic value of Gumbel corresponding to the probability p. In Table 5, it is also indicated the excitation block whose maximum is the nearest to the characteristic value $X c$, which is considered as the block of the characteristic excitation.
Table 4. Maximum horizontal displacements of the node 21 .

\begin{tabular}{|c|c|c|c|c|}
\hline \multirow{2}{*}{ 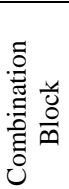 } & \multicolumn{2}{|c|}{$\begin{array}{c}\text { Rigid } \\
\text { (14 harmonics) }\end{array}$} & \multicolumn{2}{|c|}{$\begin{array}{c}\text { Semi-rigid } \\
\text { (15 harmonics) }\end{array}$} \\
\hline & $\begin{array}{l}\text { Max. Disp. } \\
\text { (m) }\end{array}$ & $\begin{array}{l}\text { Time } \\
\text { Step }\end{array}$ & $\begin{array}{l}\text { Max. Disp. } \\
\text { (m) }\end{array}$ & $\begin{array}{l}\text { Time } \\
\text { Step }\end{array}$ \\
\hline 1 & -0.0213338 & 7349 & -0.0482124 & 5346 \\
\hline 2 & -0.0252731 & 30988 & 0.0578833 & 131 \\
\hline 3 & -0.0286867 & 12410 & 0.0547532 & 56544 \\
\hline 4 & 0.0223641 & 42257 & -0.0530501 & 138 \\
\hline 5 & -0.0256064 & 44293 & -0.0508842 & 70425 \\
\hline 6 & 0.0344699 & 461 & -0.0633749 & 35024 \\
\hline 7 & 0.0248601 & 25985 & -0.0587732 & 13399 \\
\hline 8 & -0.0257005 & 71775 & 0.0570578 & 22580 \\
\hline 9 & -0.0255608 & 34042 & 0.0491359 & 23323 \\
\hline 10 & 0.0275380 & 46095 & 0.0591847 & 46044 \\
\hline 11 & 0.0248512 & 79584 & -0.0490518 & 28854 \\
\hline 12 & -0.0232195 & 55771 & 0.0635466 & 48180 \\
\hline 13 & -0.0249795 & 45838 & 0.0555469 & 128 \\
\hline 14 & 0.0360649 & 90 & -0.0639735 & 54273 \\
\hline 15 & -0.0293146 & 37492 & 0.0627561 & 78725 \\
\hline 16 & 0.0280908 & 13982 & 0.0572637 & 76542 \\
\hline 17 & 0.0250417 & 21853 & 0.0543053 & 52487 \\
\hline 18 & 0.0293981 & 5461 & -0.0507082 & 62164 \\
\hline 19 & 0.0246079 & 78601 & 0.0556747 & 65913 \\
\hline 20 & -0.0273830 & 66197 & -0.0637699 & 67028 \\
\hline
\end{tabular}

Table 5. Analysis of extremes (Gumbel).

\begin{tabular}{|c|c|c|}
\hline \multirow{2}{*}{ Parameters } & \multicolumn{2}{|c|}{ Structure } \\
\cline { 2 - 3 } & Rigid & Semi-rigid \\
\hline$\mu(\mathrm{cm})$ & 2.672 & 5.645 \\
\hline$\sigma(\mathrm{cm})$ & 0.355 & 0.512 \\
\hline$p$ & $95.0 \%$ & $95.0 \%$ \\
\hline$\varpi$ & 2.970 & 2.970 \\
\hline$\alpha$ & 3.618 & 2.504 \\
\hline$x_{b}$ & 2.512 & 5.414 \\
\hline$X c$ & 3.333 & 6.600 \\
\hline Block & $6(3.447 \mathrm{~cm})$ & $14(6.397 \mathrm{~cm})$ \\
\hline
\end{tabular}

In Table 6 the results of the combined analysis (CA) are indicated. They were obtained through the sum of $48 \%$ of the values given by the static analysis (SA) with the values resulting from the analysis for Monte Carlo simulation (MCS), respectively. The parameters used for the sake of comparison have benn the top displacement of the frame (DT), the support reaction (compression force) in the base, that is at the leeward end (RA), and the member force (traction force) in the amount of the windward base (AE).

Table 6. Table of combined analysis.

\begin{tabular}{|c|c|r|c|c|}
\hline \multirow{2}{*}{ Structure } & Parameters & \multicolumn{1}{|c|}{ SA } & MCS & $\begin{array}{c}\text { CA } \\
(48 \% \text { SA + MCS) }\end{array}$ \\
\hline \multirow{2}{*}{$\begin{array}{c}\text { Rigid } \\
(\mathrm{Bl} .6)\end{array}$} & DT (cm) & 11.9610 & 3.4470 & 9.1880 \\
\cline { 2 - 5 } & RA (KN) & 5.6413 & 1.6313 & 4.3391 \\
\cline { 2 - 5 } & AE (KN) & 5.6423 & 1.6315 & 4.3398 \\
\hline \multirow{2}{*}{$\begin{array}{c}\text { Semi }- \\
\text { Rigid } \\
(B l .14)\end{array}$} & DT (cm) & 25.6040 & 6.3970 & 18.6870 \\
\cline { 2 - 5 } & RA (KN) & 5.2820 & 1.3248 & 3.8602 \\
\cline { 2 - 5 } & AE (KN) & 5.2825 & 1.3249 & 3.8605 \\
\hline
\end{tabular}


The analysis of Table 6 shows that, considering the dynamic effects of the wind, one obtains smaller values of top displacement than those obtained statistically according to the Brazilian Code NBR-6123 (1987). The same occurs with the extremity actions and foundation reactions.

Comparing the analysis of the frames with rigid connections and with semi-rigid connections, one notices from the values presented in Table 4 and 6 that the top displacements of the frame with semirigid joints are approximately two times larger than those obtained for the rigid frame. In the case of the member forces and support reactions, the values obtained considering the semi-rigid joints are slightly smaller than those obtained for the rigid frame.

For the present example, the consideration of the dynamic effects of the wind may lead to a more economic dimensioning of the structure. Moreover, the semi-rigidity consideration may demand caution in respect to the conditions of limit state of service.

The evolutions of the top displacements (node 21) of the frame with rigid connections and with semi-rigid ones are shown in Fig. 7 and Fig. 8, respectively. Through the analysis of these figures it is noticed that the amplitude of vibration of the semi-rigid frame is greater than the one of the rigid frame.

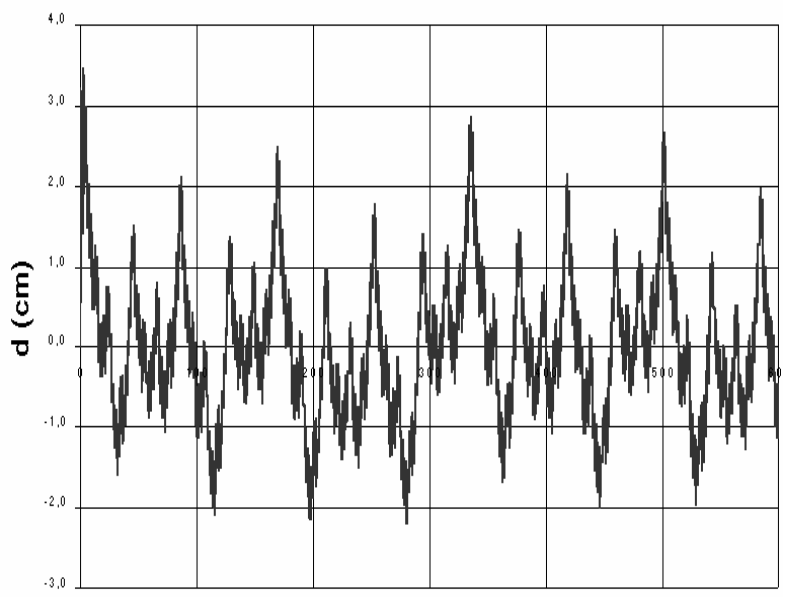

$t(s)$

Figure 7. Evolution of the horizontal displacement of the node 21 (rigid frame).

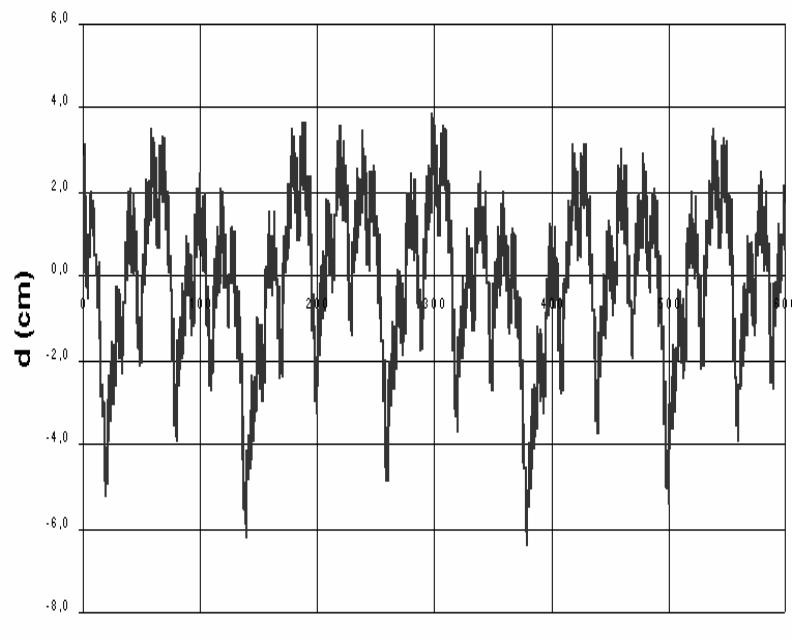

$t(s)$

Figure 8. Evolution of the horizontal displacement of the node 21 (semirigid frame).

\section{Conclusions}

It was verified, at the present work, that the semi-rigidity of the connections can alter significantly the natural frequencies, the correspondent vibration modes and the maximum displacements of the structural frame.

Taking into consideration the specific case of wind loading, the variation of rigidity at the joints may displace the resonant component of the structure, regarding the wind spectrum considered, which alters the distribution and magnitude of the decomposed harmonical components, and, consequently, the entire structural response. The studied example at the present work shows that the combined analysis, in which part of the loading is static and the other part is fluctuating, offers smaller structural responses than the corresponding responses obtained from the respective static analysis.

\section{Acknowledgements}

This work was partly supported by CNPq and Capes (Brazil).

\section{References}

Associação Brasileira De Normas Técnicas - ABNT, “NBR-6123: Forças Devidas ao Vento em Edificações”. Rio de Janeiro, 1987.

Blessmann, J., "Forças Devidas ao Vento em Edificações Altas", Porto Alegre CPGEC/UFRGS, 1988 (Caderno de Engenharia, 27).

"Canadian Structural Design Manual”. Supplement N.4 to the National Building Code of Canadá, Ottawa, 1985.

Chan, S. L. \& Ming Ho, G. W., "NonlinearVibration Analysis of Steel Frames with Semi-Rigid Connections", Journal of Structural Engineering, vol.120, pp.1075-1087, 1994.

Davenport, A. G., "The Relationship of Wind Structure to Wind Loading", Proc: 1st "Conference on Wind Effects on Building and Structures" National Physical Laboratory, Teddington, England, 1965, [Symposium N.16, 26-28/06/1963].

Franco, M., "Direct Along-Wind Dynamic Analysis of Tall Structures", Boletim Técnico da Escola Politécnica da USP, BT/PEF/9303, São Paulo, 1993.

Guimarães, M. J. R., “Análise Estática e Dinâmica de Torres Metálicas Autoportantes”, Dissertação de Mestrado em Estruturas, Publicação E.DM 001A/00, Departamento de Engenharia Civil e Ambiental, Universidade de Brasília, Brasília, DF, 2000.

Jones, S. W., Kirby, P. A. \& Nethercot, D. A., "The Analysis of Frames with Semi-Rigid Connections - A State-of-the-Art Report”, Journal of Constructional Steel Research, vol.3(2), pp.2-13, 1983.

Lee, S., Moon, T., "Moment-rotation model of semi-rigid connections with angles”, Engineering Structures, vol.24, pp.227-237, 2002.

Lui, E. M. \& Chen, W. F., "Steel Frame Analysis with Flexible Joints", Journal of Constructional Steel Research, vol.8, pp.161-202, 1987.

Osman, A., Ghobarah, A. \& Korol, R. M., "Seismic Performance of Moment Resisting Frames with Flexible Joints”, Engineering Structures, vol.15, pp.117-134, 1993.

Paz, M., "Dinámica Estructural - Teoría y Cálculo", Reverté S. A., Barcelona, 1992.

Popov, E. P., Takhirov, S. M., "Bolted large seismic steel beam-tocolumn connections Part 1: experimental study", Engineering Structures, vol.24, 1523-1534, 2002.

Sahlit, C. L. \& Soares Filho, M., "Influência das Juntas Semi-rígidas no Comportamento Dinâmico de Pórticos Planos”, Congresso Brasileiro de Engenharia Mecânica - COBEM, CD-ROM, Bauru, SP, Brasil, 1997.

Shi, G. \& Atluri, S. N., "Static and Dynamic Analysis of Space Frames With Non-Linear Flexible Connections”, International Journal for Numerical Methods in Engineering, vol.28, pp.2635-2650, 1989.

Soares Filho, M., Análise Elástica e Elastoplástica de Pórticos Planos Submetidos a Excitações Dinâmicas com a Consideração de Conexões Semirígidas, Dissertação de Mestrado em Estruturas, Publicação E.DM 008A/97, Departamento de Engenharia Civil e Ambiental, Universidade de Brasília, Brasília, DF, 1997.

Soares Filho, M. \& Sahlit, C. L., "Vibrações Livres de Estruturas Reticuladas com Conexões Semi-rígidas”, Anais da XXVIII Jornadas Sul- 
Americanas de Engenharia Estrutural, pp.1791-1800, São Carlos, SP, Brasil, 1997a.

Soares Filho, M. \& Sahlit, C. L., "Resposta Dinâmica de Estruturas Semi-rígidas como um Problema de Complementaridade Linear”, Anais do
XVIII Congresso Ibero Latino-Americano sobre Métodos Computacionais para Engenharia (XVIII CILAMCE), pp.127-134, Brasília, Brasil, 1997b.

Stelmack, T. W., Marley, M. J. \& Gerstle, K. H., “Analysis and tests of flexibly connected steel frames”, Journal of Structural Engineering, ASCE, vol.112, 1573-1588, 1986. 